\title{
The Establishment of Child Health Cadre as Prevention for Foodborne Disease at Primary Schools
}

\author{
Fariani Syahrul, Chatarina U. W., Arief Hargono \\ Department of Epidemiology, Universitas Airlangga, Surabaya, Indonesia
}

\section{Article Info}

Article history:

Received Mar 10, 2017

Revised May 6, 2017

Accepted May 21, 2017

\section{Keywords:}

Child health cadre

Foodborne diseases

Prevention

\begin{abstract}
Personal health, including health on school-age children comes from food intake. But often, these foods can cause health problems, such as foodborne diseases. A quasi-experimental study was conducted to monitor the Clean and Healthy Lifestyle (CHL) of children at school through the establishment and evaluation of child health cadres. Phases of activities are the selection of child health cadres (10 children), training and determination of the child that will be monitored (40 children), preliminary assessment on the monitored CHL, two-month monitoring and final assessment. Monitored CHL are the CHL associated with foodborne diseases such as clean nails, snacks habit, habit of bringing lunch, and hand-washing habit in schools. Descriptive analysis showed that there were differences between the CHL school children before and after the monitoring conducted by child health cadres, however the results of the Chi-Square Test indicated that only the habit of bringing lunch that yield a significant change $(\mathrm{p}=0.01)$. Evaluation of the routine activity showed that the average cadre activity on monitoring is $75.7 \%$ and the average of completeness monitoring books is $91.9 \%$. The activities of child health cadres can be applied on an ongoing basis with the school health program activities that have been established inschools.
\end{abstract}

Copyright (c) 2017 Institute of Advanced Engineering and Science. All rights reserved.

Corresponding Author:

Fariani Syahrul,

Department of Epidemiology,

Universitas Airlangga,

Kampus C Unair, Jl.Mulyorejo Surabaya, Indonesia.

Email: fariani_syahrul@yahoo.com

\section{INTRODUCTION}

School children are the next generation and the strategic assets for development, thus they are expected to be healthy, intelligent and productive. The quality of children as the next generation is determined by two factors which are interrelated and interdependent, namely education and health. For this reason, it is important to protect children from the risks of health problems. Elementary School Age (approximately 6-12 years old) is the time when children are fond of playing and eating snacks (including street food outside the school complex), therefore they are at risk for various health problems. One of the factors determining one's health, including those of school children, is the food intake. But often, these foods people consumed may pose a health problem instead. Consumption of snacks containing chemical or biological contamination is very dangerous for children's health and safety. This behavior can lead to contraction of foodborne diseases.

Foodborne diseases (FBDs) are any disease resulting from the consumption of contaminated food and/or drink, caused by various microorganisms or microbial pathogens that contaminate food or drink. FBDs caused by microbes occur through water contamination, cutlery/drinking utilities, hand and intermediary vectors such as flies and cockroaches. Types of FBDs include food poisoning, diarrhea, dysentry, typhoid, cholera, and others [1-2]. 
Foodborne diseases are important worldwide, resulting in considerable morbidity and mortality [3]. Assessing the foodborne diseases is complicated because many different microbial pathogens can be transmitted by food, humans, water and animal reservoir [4-5]. The relative impact of each route differs depending on the epidemiology of the disease causing microorganism [6]. In developed countries, it is estimated that the rate of foodborne diseases may be 10-350 times higher than the reported cases [7]. Various studies have found that the type of agent on FBDs incident is enteric, parasitic, and chemical [8]. One type of most common FBDs are diarrhea. The results showed that episodes of diarrhea per year in children are quite high at 3.2 to 4.6 episodes, with $70 \%$ of which are caused by contaminated food [9]. The results of Basic Health Research in 2007 showed that the prevalence rate of diarrhea in Indonesia is around 42.2\%. In schoolage children (5-14 years), the numbers of diarrhea ranks the 5th highest after the age groups of infant, toddler and the elderly, amounting to $9.0 \%$. Typhoid in the group of school-age children occupies the highest prevalence compared to all other age groups, amounting to 1.9\%. Research results from BPOM (Agency for Food and Drug Administration) in 2007 in Surabaya showed that within 700 students from primary schools in the sub district Genteng, $60 \%$ of them still consumed street food from outside the school. Ironically, the majority of snacks from street food are unhealthy snacks. The research of five elementary schools in the region of East Surabaya showed that $59.7 \%$ of students always buy snacks in schools; $36.1 \%$ sometimes buy snacks at school and only $4.2 \%$ of students never buy snacks at school [10].

Occurrences of FBDs, such as diarrhea and typhoid in school children, were still sufficient susceptible. Lack of clean and healthy behavior became the primary cause, so that the contaminated agent can easily enter to the body through the food consumed [11]. Some factors that allegedly can reduce the occurrence of foodborne diseases are hand-washing habits, customs school snacks, bringing snacks/lunch to school, and others. Snacks are food and drink produced by the informal sector entrepreneurs with small assets [12]. These snacks are ready to be consumed and sold in public places, in the street and in the housing area by mobile street hawker, or in street stalls, or combination of both methods. In this case, snacks can be main meal or food interlude. Based on the background and the study of the problem, this research on the Clean and Healthy Lifestyle (CHL) of children at school was conducted by doing intervention in form of monitoring by children health cadre. The objective of this research is to monitor the Clean and Healthy Lifestyle (CHL) of children at schools through the establishment and evaluation of children healthcadres.

\section{RESEARCH METHOD}

The type of research is a quasi-experimental. The research sample consisted of 40 students of $4^{\text {th }}$ and $5^{\text {th }}$ grade in Elementary School Surabaya. The location was chosen based on the results of previous studies [2]. Intervention was done by establishing children health cadres. For this purpose, 10 children were asked to monitor the Clean and Healthy Lifestyle (CHL) of students at school, where each of children health cadre will monitor four children. Control of potential confounding variable was done with restriction. Restriction is research activity to control confounding by limiting the study to a subject who has the same level of the confounding factors [13]. The location of this study was only one school to obtain homogeneous conditions from the school environment including hand-washing facilities, canteen, and foodstreets.

There were six stages of activities: (1) the selection of children health cadre (10 children) by providing questionnaires to all students in grade 4 and grade 5 to assess their levels of knowledge about the Clean and Healthy Lifestyle (CHL); (2) the training of selected children health cadre; (3) determining the children that will be monitored (40 children); (4) preliminary assessment of CHL (nail hygiene and hand washing, the habit of bringing lunch and having snack at school); (5) implementation of monitoring by children health cadre duration of 2 months, and (6) the final assessment of CHL in children being monitored. The children health cadre is equipped with monitoring books as a tool for conducting monitoring. Each cadre will monitor 4 children with frequency of 2 times per week for the duration of 2 months.

The implementation of data collection and monitoring activities is done after the parents of the research subjects (10 cadres and 40 students) signed informed concern. Ethical clearencesertificates are issued by Faculty of Public Health, Airlangga University. The data were analyzed descriptively to describe the study variables, meanwhile to assess the results of pre-test and post-test monitoring different proportion test was held (Chi-square test with $\alpha=0.05$ ). In addition, an evaluation on the performance of children health cadre includes monitoring and completing monitoring books.

\section{RESULTS AND ANALYSIS}

\subsection{Characteristics of student}

The average age of the student was 10.04 years old (range between 9-13 years old). Most of the student were girls (54.6\%) and $45.4 \%$ were boys. Most students were given pocket money by their parents 
(79.8\%), while the rest $20.2 \%$ of students were only occasionally given pocket money. This means that every student might bring money to school at least once. The average money brought by the students was IDR 3,558.82 (range between IDR 1,000.00 - IDR 10,000.00).

\subsection{Description of student'sCHL}

The student's CHL being monitored were nail conditions (trimmed, long, clean or dirty), hand washing habits, habits of bringing lunch and buying snacks at school. Children health cadre monitored CHL twice a week for 2 months, so there were 8 times of observation. Conditions pre- and post-monitoring were used in analysis toward the differences in CHL. The results showed that there was a rise in the percentage of children whose nails were clean and trimmed during post-monitoring. The percentage of children with long and unkempt fingernails fell during post monitoring. However, the results of the Chi-Square test have significance value of $>0.05$ ( $\mathrm{p}=0.135$ for trimmed/long nails and $\mathrm{p}=0.316$ for clean/dirty nails), so there is no significant difference in the condition of student nails between pre- and post-monitoring by children health cadre. This is in fact very unfortunate because fingernails are very likely to be a medium for the transmission of foodborne diseases. During the monitoring, the children health cadre observed the condition of their classmates' nails. The results of previous studies showed that there was a relationship between the numbers of microbes (E. coli) with the length of fingernails; with higher number of microbes are found under long fingernails [14]. The complete results can be seen in Table 1.

Table 1. Description of The Student Nail Condition Based on Pre- and Post-Monitoring by Children Health Cadre

\begin{tabular}{ccccc}
\hline \multirow{2}{*}{ Nail condition } & Pre-monitoring & Post-monitoring \\
& $\mathrm{N}$ & $\%$ & $\mathrm{n}$ & $\%$ \\
\hline Clean & 31 & 77.5 & 33 & 82.5 \\
Dirty & 9 & 22.5 & 7 & 17.5 \\
$\mathrm{~N}$ & 40 & 100.0 & 40 & 100.0 \\
Trimmed & 25 & 62.5 & 30 & 75.0 \\
Long & 15 & 37.5 & 10 & 25.0 \\
$\mathrm{~N}$ & 40 & 100.0 & 40 & 100.0 \\
\hline
\end{tabular}

The habit of hand washing with soap in schools is already good. It is shown by an increase during post-monitoring, and as a contrary, the percentage of children who wash their hands without soap decreases. However there is a bad sign in the rise of the percentage of students who do not wash their hands during postmonitoring. This condition yields results of the Chi-Square test with significant value of $>0.05(\mathrm{p}=1,000)$. This suggested that the children health cadre has no influence on changing the hand washing habit on student. This bad habit is very prone to the risk of being infected by foodborne diseases. The result of previous studies showed that the risk of foodborne diseases (diarrhea and typhoid) in children who do not wash hands before eating is 4.43 times greater than children who have hand washing habit [11]. Food/beverage is very easily contaminated with microbes from unclean hands, which can cause health problems if the food/beverage is consumed. So, hand washing can prevent the spread of foodborne diseases [15]. The complete results can be seen in Table 2.

Table 2. Description of Handwashing Habit at School Based on Pre- and Post-Monitoring by Children Health Cadre

\begin{tabular}{lcccc}
\hline \multicolumn{1}{c}{ Hand washing habit at school } & $\mathrm{N}$ & Pre-monitoring & \multicolumn{2}{c}{ Post-monitoring } \\
& 1 & 2.5 & 4 & $\%$ \\
\hline Hand washing with soap & 25 & 62.5 & 12 & 30.0 \\
Hand washing without soap & 14 & 35.0 & 24 & 60.0 \\
Did not wash hands & 40 & 100.0 & 40 & 100.0 \\
$\mathrm{~N}$ & & &
\end{tabular}

The results of a descriptive study showed the differences in the habit of carrying lunch between preand post-monitoring. The percentage of children who bring lunch rises during post-monitoring. In contrary, the number of students who were not used to bring lunch decreased during post-monitoring. Chi-square test results showed that there were differences in the habit of bringing lunch $(\mathrm{p}=0.010)$ between the pre- and post-monitoring. It is good habits because this way the food/beverage consumed are generally cleaner and more secure from the danger of microbial contamination. In fact, most of the students who bring their own lunch still have a habit of buying snacks at school, due to their long study hour at school (about 6 hours). 
Students need more food intake while at school. On the other hand, the monitoring conducted by the children health cadre has indeed influenced the habit of brings lunch to school in some student who was monitored. By bringing lunch to school, students' food safety is more assured rather than buying snack outside school.

The next results showed that the majority of students have a habit of consuming snacks at school, both in the school cafetaria and snack-stalls outside the school area (street food) either during pre- or postmonitoring. There is no significant difference between pre- and post-monitoring for this subject $(p=0.507)$. Eating snacks is very popular among students. The habit of buying snacks at school is very difficult to change. There are many factors that shaped this habit, such as the need for food intake during the long school hours and also the fact that children love rich taste of food like sweet, savory and sour. For these reasons, it was easy for street food sellers to attract children to buy snacks from them. Therefore, it is very difficult to change student habit for buying snack outside the school area, even after they have been monitored. The problem is that the products offered by the street food sellers are often lack in nutrients or contain ingredients that are harmful or prone to microbial contamination. The results of research in different countries and different times showed that street food is a source of microbial infection. Research by taking samples of salami (a type of dry sausage) and hamburgers on laboratory tests indicated that the food had become a transmission source of E. coli O157: H7 [16]. Other studies with fast foods samples, also found that there were some microbes in food, such as Salmonella sp, E. coli, S. aurous, B. Cereus, and P. aeruginosa [17]. Similarly with researches conducted in Indonesia, confirming the presence of Escherichia coli bacteria contamination in food and beverage samples taken in Primary Schools [18]. Food becomes less secure, mostly because of biological agents such as Salmonella, Campylobacter, and Escherichia coli. There are many other agents that make food unsafe [19]. Snacks safe for consumption should not contain dangerous hazard comprising of biological/microbiological, chemical and physical contamination that can harm and endanger human health [20]. Due to the increasing need for snacks and food intake at school, there should be a school canteen with direct supervision from the teachers. The complete results can be seen in Table 3.

Table 3. Description of The Habit of Bringing Lunch and Buying Snacks (Snacking) at School on Pre- and Post-Monitoring by Children Health Cadre

\begin{tabular}{ccccc}
\hline Eating habit at school & \multicolumn{2}{c}{ Pre-monitoring } & \multicolumn{2}{c}{ Post-monitoring } \\
n & $\mathrm{n}$ & $\%$ & \multicolumn{2}{c}{$\%$} \\
\hline Have a habit of bringing lunch/snack from home & & & & \\
Yes & 15 & 37.5 & 24 & 60.0 \\
No & 25 & 62.5 & 16 & 40.0 \\
N & 40 & 100.0 & 40 & 100.0 \\
Buying snacks (snacking) at school & & & & \\
Yes : & 0 & 0 & 1 & 2.5 \\
Buying snacks at school cafeteria & 4 & 10.0 & 0 & 0 \\
Buying snacks at school cafeteria and street stalls & 31 & 77.5 & 34 & 85.0 \\
Buying snacks at street stalls & 5 & 12.5 & 5 & 12.5 \\
No & 40 & 100.0 & 40 & 100.0 \\
N & & & &
\end{tabular}

\subsection{The evaluation of children healthcadre}

The evaluation conducted consists of Process Evaluation and Result Evaluation on the implementation of monitoring activities carried out by children health cadre for 8 weeks upon their classmates. The process evaluation includes the implementation of monitoring activities and the signing of monitoring books by class teachers every Saturday.

The results of the process evaluation are as follows: 1) All cadres say that there is no difficulty in carrying out the monitoring and filling out the monitoring books; 2) One child health cadre (10\%) could not continue the monitoring activities at the 6th week because of illness. The monitoring was postponed and continued after the cadre went back to school; 3) All the monitoring books have been signed by class teachers every Saturday. After the completion of monitoring activities, an evaluation of the work of children health cadre was conducted, especially on the monitoring routine and completion of the monitoring books. Result evaluation on the routine showed that the average of cadre members routinely monitoring that target's CHL was $75.7 \%$ (range between $29 \%-100 \%$ ), while the average completion of monitoring books by cadres was $91.9 \%$ (range between $80 \%-100 \%$ ). The complete results can be seen in Table 4.

The monitoring performed by children health cadre did not strongly affect on improving CHL at school, except on the variable of bringing lunch from home. It may be necessary to conduct further research with a longer monitoring time so that visible improvement relating to CHL on students can be seen. Behavior change requires a relatively long time and must be supported by the environment and the availability of infrastructure, for example the availability of adequate school canteen, the availability of hand-washing 
facilities near the children playground as well as providing food health guidance for street food vendors around the school. This way, the children health cadre as health promotion ambassador can perform their roles optimally. The results of a study aimed to assess the relationship between teenagers' consuming behavior on food around the school recommends that school programs aimed for the promotion of healthy foods should be the target for improving a healthy school environment [21].

Table 4. Result Evaluation on The Performance of Children Health Cadre

\begin{tabular}{cccc}
\hline Grade & Children Health Cadre & Routine & Completion \\
\hline IV & A & $71 \%$ & $100 \%$ \\
& B & $71 \%$ & $100 \%$ \\
& C & $100 \%$ & $80 \%$ \\
V & D & $29 \%$ & $80 \%$ \\
& E & $100 \%$ & $89 \%$ \\
& F & $100 \%$ & $96 \%$ \\
G & $93 \%$ & $96 \%$ \\
& H & $93 \%$ & $100 \%$ \\
& I & $29 \%$ & $94 \%$ \\
& J & $71 \%$ & $84 \%$ \\
& & $75.7 \%$ & $91.9 \%$ \\
\hline
\end{tabular}

\section{CONCLUSION}

The analysis result on the differences of student CHL between pre- and post-monitoring conducted by children health cadre showed only changes in one variable of bringing lunch from home. Evaluation on the children health cadre concluded that their performance was quite successful, with percentage of routine activities and completion of monitoring was above $75 \%$. However, the monitoring by children health cadre had not been able to significantly change the students' CHL, except the habit of bringing lunch. Monitoring activities by the children health cadre can be applied on an ongoing basis, along with the school health program that have been established at schools.

\section{ACKNOWLEDGEMENTS}

We are gratefully acknowledged to Faculty of Public Health, Airlangga University, Indonesia. Special thanks to all subjects who participated in the study are gratefully acknowledged.

\section{REFERENCES}

[1] J. A. Rozendaal, "Vector control: Methods for use by individuals and communities," WHO, Geneva, 1997.

[2] P. R. Torgerson, et al., "The global burden of foodborne parasitic diseases: An update," Trend in Parasitology; 30(1), 2014

[3] M. D. Kirk, et al., "World Health Organization Estimates of the Global and Regional Disease Burden of 22 Foodborne Bacterial, Protozoal, and Viral Diseases, 2010: A Dara Synthesis," Plos Medicine,2015.

[4] A. H. Havelaar, et al., "Disease Burden of Foodborne Pathogens in the Netherlands, 2009," International Journal of Food Microbiology, vol. 156, pp. 231-238,2012.

[5] M. A. Croxen, et al., "Recent Advances in Understanding Enteric Pathogenic Escherichia coli," Clinical Microbiology Reviews, vol/issue: 26(4), pp. 822-880,2013.

[6] T. Hald, et al., "World Health Organization Estimates of the Relative Contributions of Food to the Burden of Disease Due to Selected Foodborne Hazards: A Structured Expert Elicitation," Plos One,2016.

[7] M. W. Borgdorff and M. Yasmine, "Food Security Issue. Foodborne Diseases Surveillance: What System Can Be Used?" WHO-ICD/SEAMEO Tropical Medicine RCCN, University of Indonesia,2005.

[8] J. A. Haagsma, et al., "Review: systemic review of foodborne disease studies: quality assessment of data and methodology," International Journal of Food Microbiology, vol. 166, pp. 34-47,2013.

[9] P. Mensah, "Foodborne Diseases Surveillance and Monitoring in Food Control," WHO,2002

[10] F. Syahrul and M. Atoillah I., "Analysis of Foodborne Diseases Risk Factors in Elementary School by Canteen at Schoo," Surabaya, Airlangga University, 2011.

[11] H. H. Sholikhah and F. Sustini, "Description of Clean and Healthy Behavior of Food Borne Disease Among by School Children Age in Babatlerawat I Elementary School, District Pakal,” Research of Health System Journal, vol/issue: 16(4), pp. 351-362,2013.

[12] B. Sandjaja, et al., "Dictionary of Nutrition - Family Health Supplement," Publisher Kompas Book, Jakarta,2009.

[13] R. Beaglehole, et al., "Basic Epidememiology," World Health Organization, 2006.

[14] C. M. Lin, et al., "A Comparison of Hand Washing Techniques to Remove Echerichia coli danCaliciviruses under Natural or Artificial Fingernails," Journal of Food Protection, vol.12, pp. 2196-2405,2003.

[15] P. S. Mead and M. G. Patricia, "Escherichia coli 0157:H7," The Lancet, vol/issue: 352(9135), pp. 1207-1212,1998. 
[16] P. R. Cieslak, et al., "Hamburger-Associated Escherichia coli O157:H7 Infection in Las Vegas: A Hidden Epidemic," American Journal of Public Health, vol/issue: 87(2),1997.

[17] M. M. Nunes, et al., "Food Control," vol. 34, pp. 235-240,2013.

[18] R. L. Puspitasari, "Quality Snacks at Elementary School," Journal Al-Azhar Indonesia, Sains Series and Technology, vol/issue: 2(1), pp. 52-56,2013.

[19] J. W. Cary, et al., "Microbial Foodborne Diseases - Mechanism of Pathogenesis and Toxin Synthesis," Technomic Publishing Company Inc. USA,2000.

[20] Ministry of Health, "Food Security Guidence in Elementary School and Madrasah Ibtidaiyah (Islamic School)," Nutrition Division, Jakarta,2012.

[21] M. Y. Kubik, et al., "The Association of the School Food Environment with Dietary Behaviors of Young Adolescent," American of Public Health, vol/issue: 93(7),2003. 